\title{
Instantaneous Void Fraction Signal Using Capacitance Sensor for Two- Phase Flow Pattern Identification
}

\author{
Joshua Rosettani, Rashal Abed, Wael Ahmed \\ University of Guelph \\ 50 Stone Rd E, Guelph, Canada \\ jrosetta@uoguelph.ca; rabed@uoguelph.ca; ahmedw@uoguelph.ca
}

\section{Extended Abstract}

Two-phase flow can be seen in petroleum, air conditioning systems, refrigeration systems, pumping technologies and power generation [1]. Two-phase flow is characterized by different flow pattern such as bubble flow, churn flow, slug flow, and annular flow behaviour[2]. Void fraction can be defined as the volumetric ratio between the gas phase to the total mixture. One of the most widely used techniques to determine void fraction is the electrical impedance by placing two electrodes on either side of the pipe and measuring the impedance between these two probes [3]. In this technique the capacitance change is related to the variation of the dielectric constants of the two phases within the sensor [4].

Minimizing the error in the capacitance readings will prove helpful in accurately identifying the flow pattern passing through the sensor. The void fraction time signal for air-water two-phase mixture will be evaluated for different two-phase flow patterns by the use of a capacitance sensor. The experimental setup consists of a Flonergia airlift pump, and controlled through mass flow meters to be able to create the different flow patterns within the vertical pipe. A concave designed sensor was mounted on the vertical pipe and connected to a DAQ system where the data is collected using LabVIEW.

To ensure accurate readings from the capacitance sensor, a calibration of the sensor was performed by taking time signals of two cases: 1. Vertical column full of liquid, 2. Vertical column full of air. This provides the two points on a linear calibration curve between void fraction and the capacitance signals. For each air-water capacitance signal, 50000 samples are collected at a sample rate of $1000 \mathrm{~Hz}$ to obtain the time signal for each case. It was determined that the average air signal was $401.5 \mu F$ and the average water signal was $412.93 \mu F$. By taking the maximum root mean square from each signal and dividing the value by the range, the error in each reading was less than $1 \%$.

The three flow regimes that were evaluated were bubbly flow, slug flow, and churn flow. The void fraction that were determined for each flow rate were $1.6 \%$ for an air flow rate of 0.5LPM, 14\% for 3.5 LPM and 21\% for 15 SLPM. It was observed that as the airflow rates increased, the void fraction also increased and the flow patterns change for bubble to slug and to churn flow. The next steps will be to evaluate the time signal for each flow pattern to understand the structure of the bubble that will be passing through the capacitance sensor. Evaluating the time signal will give a better understanding of the flow pattern that is in operation. In addition, the void fraction for a range of flow conditions can be compared with flow visualization to accurately determine the flow pattern.

\section{References}

[1] R. Srisomba, O. Mahian, A. S. Dalkilic, and S. Wongwises, "Measurement of the void fraction of R-134a flowing through a horizontal tube," Int. Commun. Heat Mass Transf., vol. 56, pp. 8-14, 2014.

[2] M. Ishii and T. Hibiki, Thermo-Fluid Dynamics of Two-Phase Flow. Springer New York, 2010.

[3] A. Pal and B. Vasuki, "Void fraction measurement using concave capacitor based sensor - Analytical and experimental evaluation," Measurement, vol. 124, no. April, pp. 81-90, 2018.

[4] W. H. Ahmed, "Capacitance Sensors for Void-Fraction Measurements and Flow-Pattern Identification in Air - Oil Two-Phase Flow,” vol. 6, no. 5, pp. 1153-1163, 2006. 